\title{
Effect of bullfrog (Rana catesbeiana) oil administered by gavage on the fatty acid composition and oxidative stress of mouse liver
}

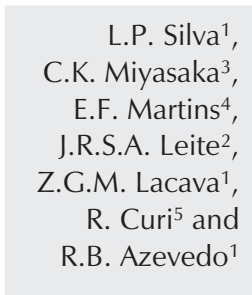

\section{Correspondence}

R.B. Azevedo

Departamento de Genética e

Morfologia, Instituto de Biologia

Universidade de Brasília

70919-970 Brasília, DF

Brasil

Fax: +55-61-349-6167

E-mail: razevedo@unb.br

Research supported by $\mathrm{CNPq}$ and PRONEX.

Publication supported by FAPESP

Received August 7, 2003

Accepted July 12, 2004

\author{
Departamentos de ${ }^{1}$ Genética e Morfologia, and ${ }^{2}$ Biologia Celular, \\ Instituto de Ciências Biológicas, Universidade de Brasília, Brasília, DF, Brasil \\ ${ }^{3}$ Departamento de Alimento e Nutrição, Faculdade de Engenharia de Alimentos, \\ Universidade Estadual de Campinas, Campinas, SP, Brasil \\ ${ }^{4}$ Centro de Ciências Biológicas e Saúde, Universidade Cruzeiro do Sul, São Paulo, SP, \\ Brasil \\ ${ }^{5}$ Departamento de Fisiologia e Biofísica, Instituto de Ciências Biomédicas, \\ Universidade de São Paulo, São Paulo, SP, Brasil
}

Abstract

The aim of the present study was to investigate the effects of daily intragastric administration of bullfrog oil (oleic, linoleic and palmitoleic acid-rich oil), corresponding to $0.4 \%$ of body weight for four weeks, on fatty acid composition and oxidative stress (lipid peroxidation and catalase activity) in mouse liver. The activities of aspartate aminotransferase (AST), alkaline phosphatase (ALP), alanine aminotransferase (ALT), and gamma-glutamyltransferase (GGT), biomarkers of tissue injury, were determined in liver homogenates and serum. The proportions of 18:2n-6, 20:4n-6, 20:5n-3, and 22:6n-3 (polyunsaturated fatty acids, from 37 to $60 \%$ ) in the total fatty acid content were increased in the liver of the bullfrog oil-treated group $(\mathrm{P}<0.05)$ compared to control. At the same time, a significant decrease in the relative abundance of 14:0, 16:0, and 18:0 (saturated fatty acids, from 49 to $25 \%$ ) was observed. The hepatic content of thiobarbituric acid reactive substances (TBARS) was increased from $2.3 \pm 0.2$ to $12.3 \pm$ $0.3 \mathrm{nmol}$ TBA-MDA/mg protein and catalase activity was increased from $840 \pm 32$ to $1110 \pm 45 \mu \mathrm{mol}$ reduced $\mathrm{H}_{2} \mathrm{O}_{2} \mathrm{~min}^{-1} \mathrm{mg}$ protein ${ }^{-1}$ in the treated group. Bullfrog oil administration increased AST and ALP activities in the liver (from $234.10 \pm 0.12$ to $342.84 \pm 0.13$ and $9.38 \pm$ 0.60 to $20.06 \pm 0.27 \mathrm{U} / \mathrm{g}$, respectively) and in serum (from $95.41 \pm$ 6.13 to $120.32 \pm 3.15$ and $234.75 \pm 11.5$ to $254.41 \pm 2.73 \mathrm{U} / 1$, respectively), suggesting that this treatment induced tissue damage. ALT activity was increased from $287.28 \pm 0.29$ to $315.98 \pm 0.34 \mathrm{U} / \mathrm{g}$ in the liver but remained unchanged in serum, whereas the GGT activity was not affected by bullfrog oil treatment. Therefore, despite the interesting modulation of fatty acids by bullfrog oil, a possible therapeutic use requires care since some adverse effects were observed in liver.
Key words

- Bullfrog oil

- Liver

- TBARS

- Catalase activity

- Lipid peroxidation

- Monounsaturated fatty acid 
Several studies have shown the influence of dietary fat on fatty acid (FA) composition and oxidative stress in various tissues (1-8). The proportion of FA in the diet is of great physiological importance since it can modulate the composition of FA in cell membrane phospholipids $(1,2)$. This is due to the competition among FA families for elongation and desaturation enzymes. Some investigators have postulated that the unsaturated/ saturated FA (SFA) ratio of the diet is an important factor for determining the intrinsic oxidative potential of tissues (3).

Oils of plant and animal origin have been used for the treatment of immune and inflammatory disorders (2). These oils contain a mixture of different types of SFA, monounsaturated FA (MUFA) and polyunsaturated FA (PUFA). Bullfrog oil contains a relatively low amount of SFA (17\% of total FA) and PUFA (28\% of total FA) and is rich in MUFA (55\% of total FA). The sum of MUFA and PUFA accounts for $83 \%$ of total FA in this oil and makes it a candidate for therapeutic purposes (2). However, there is no report on the effects of bullfrog oil on animals.

In the present study, the effects of the MUFA-rich bullfrog oil on FA composition and oxidative stress (lipid peroxidation and catalase activity) were investigated in mouse liver. The liver and serum activities of aspartate aminotransferase (AST), alanine aminotransferase (ALT), alkaline phosphatase (ALP), and gamma-glutamyltransferase (GGT) were also determined to assess the occurrence of injury in the organ. Bullfrogs can be easily grown to provide meat and perhaps oil for therapeutic purposes.

Male Swiss mice (25-30 g) were divided into two groups of 6 animals each fed Purina commercial chow (5\% fat), with free access to water. The number of animals used in this study was sufficient as indicated by the small standard error of the means and by previous work using the same methodology (5).

The animals received sterile saline solution (control group,) or bullfrog oil intragas- trically daily for 4 weeks. The FA composition of bullfrog oil (\%) is presented in Table 1 . The amount of oil ( $0.4 \%$ of body weight) administered as a supplement was recalculated daily on the basis of changes in body weight assuming that the daily food intake of a mouse is approximately $10 \%$ of body weight, which corresponds to $0.4-0.5 \mathrm{~g}$ fat. Therefore, the supplementation of oil at $0.4 \%$ body weight increased by 2 -fold the amount of ingested fat. Bullfrog oil was given by gavage to avoid the oxidation/peroxidation of FA which occurs during the preparation of a fatrich diet. At the end of the study period, mice were killed by decapitation and livers were removed and stored at $-80^{\circ} \mathrm{C}$.

For total lipid extraction, frozen samples were homogenized in methanol and chloroform, followed by the addition of an aqueous solution of $\mathrm{KCl}$; after vortexing, the upper layer phase was discarded. The FA were saponified with an alcoholic solution of $\mathrm{NaOH}$ and then extracted twice with $\mathrm{HCl}$ and hexane as described elsewhere (9). FA were derivatized with 4-bromomethyl-7-coumarin and the composition was analyzed by high performance liquid chromatography (Shimadzu model LC-10A, Kyoto, Japan) using a $\mathrm{C} 8$ column with a $\mathrm{C} 8$ pre-column, eluted with $1 \mathrm{ml} / \mathrm{min}$ acetonitrile/water (77:23, by volume) and the effluent was monitored with a fluorescence detector (325$\mathrm{nm}$ excitation and 395-nm emission) (9). FA used as standards were obtained from Sigma (St. Louis, MO, USA). Intra- and interassay coefficients of variation $(\mathrm{CV})$ were less than $8 \%$. FA composition is presented in Table 1 as percent of the total identified FA.

The unsaturation indexes of the FA present in bullfrog oil and liver were calculated as described in Ref. 10. The percentage of each FA was multiplied by the number of double bonds present. The sum was calculated and the values are presented in Table 1.

For the determination of thiobarbituric acid reactive substances (TBARS), frozen liver samples were homogenized in phos- 
phate buffer containing butylated hydroxytoluene and 2-thiobarbituric acid. After incubation at $100^{\circ} \mathrm{C}$ for $30 \mathrm{~min}$, the mixture was cooled and the TBARS adducts were extracted with butanol and centrifuged at $1600 \mathrm{~g}$ at $4^{\circ} \mathrm{C}$ for $30 \mathrm{~min}$. The supernatant phase (butanol phase) was collected and absorbance at $532 \mathrm{~nm}$ was measured with a Pharmacia Biotech Ultrospec 3000 Spectrophotometer (Uppsala, Sweden) (11). TBARS are reported as $\mu \mathrm{mol} / \mathrm{mg}$ protein using a molar absorptivity of $1.56 \times 10^{-5} \mathrm{M}^{-1} \mathrm{ml}^{-1}$.

For the determination of hepatic catalase activity, samples were homogenized in phosphate buffer and centrifuged, and the supernatant was used for analysis. Catalase activity was determined in duplicate by monitoring the decomposition of $\mathrm{H}_{2} \mathrm{O}_{2}$ at $30^{\circ} \mathrm{C}$ with a UV visible spectrophotometer at $230 \mathrm{~nm}$ (12). Catalase specific activity is reported as $\mu$ mol reduced $\mathrm{H}_{2} \mathrm{O}_{2} \min ^{-1} \mathrm{mg}$ protein ${ }^{-1}$. The protein content of the liver homogenates was measured by the method of Bradford (13).

ALT, AST, ALP, and GGT activities were determined in serum and liver using a Bayer ADVIA 1650 clinical chemistry analyzer (Lerverkusen, Germany) according to manufacturer instructions. The liver was homogenized in $0.2 \mathrm{~g} / \mathrm{ml}$ phosphate-buffered saline, $\mathrm{pH}$ 7.4. Blood samples were collected into test tubes and allowed to stand for 30 min to clot before centrifugation at $300 \mathrm{~g}$ for $10 \mathrm{~min}$. The serum was separated, transferred to other tube, and stored at $4^{\circ} \mathrm{C}$ for subsequent analysis.

All data are reported as means \pm SEM. The results were submitted to one-way ANOVA, and means were compared between groups by Scheffé's test. Results were considered statistically significant when $\mathrm{P}<0.05$.

The dose of bullfrog oil administered did not cause diarrhea or any other visible clinical symptoms in the animals. Mice of both groups were healthy and had similar final body weights $(27.2 \pm 0.6$ for controls and $26.3 \pm 0.3 \mathrm{~g}$ for bullfrog oil-treated animals).

Liver FA composition was changed by bullfrog oil administration (Table 1). The proportion of SFA was decreased by $48 \%$, with a significant reduction in the relative abundance of 14:0 (63\%), 16:0 (44\%), and 18:0 (54\%; $\mathrm{P}<0.05)$. Conversely, the proportion of PUFA was increased 62\% $(\mathrm{P}<$ 0.05 ) and the PUFA/SFA ratio was increased $213 \%$ ( $\mathrm{P}<0.05)$. The most altered PUFA class was $n$-3 PUFA, which increased $143 \%$ $(\mathrm{P}<0.05)$. The significant $(\mathrm{P}<0.05)$ increase of $n$-6 PUFA was much smaller (34\%). The $n-3$ PUFA $n-6$ PUFA ratio was also increased $81 \%(\mathrm{P}<0.05)$. Among the $n-3$

Table 1. Fatty acid composition of bullfrog oil and of the liver of bullfrog oil-treated mice.

\begin{tabular}{|c|c|c|c|}
\hline \multirow{2}{*}{ Fatty acids (\%) } & \multirow[t]{2}{*}{ Bullfrog oil } & \multicolumn{2}{|c|}{ Liver } \\
\hline & & Control group & $\begin{array}{c}\text { Bullfrog oil-treated } \\
\text { group }\end{array}$ \\
\hline $12: 0$ & 0.21 & $0.50 \pm 0.02$ & $0.59 \pm 0.03$ \\
\hline $14: 0$ & 2.77 & $1.76 \pm 0.06$ & $0.65 \pm 0.02 *$ \\
\hline 16:0 & 11.91 & $27.90 \pm 1.15$ & $15.58 \pm 0.72 *$ \\
\hline $16: 1(n-9)$ & 17.31 & $2.45 \pm 0.09$ & $3.03 \pm 0.08$ \\
\hline $18: 0$ & 2.34 & $18.35 \pm 0.65$ & $8.51 \pm 0.40^{*}$ \\
\hline $18: 1(n-9)$ & 37.60 & $12.38 \pm 0.43$ & $11.93 \pm 0.54$ \\
\hline $18: 2(n-6)$ & 23.78 & $14.46 \pm 0.78$ & $20.50 \pm 0.93^{*}$ \\
\hline $18: 3(n-3)$ & 1.97 & $0.53 \pm 0.01$ & $0.21 \pm 0.02 *$ \\
\hline $20: 4(n-6)$ & 0.74 & $11.95 \pm 0.77$ & $15.37 \pm 0.54^{*}$ \\
\hline $20: 5(n-3)$ & 0.46 & $0.83 \pm 0.03$ & $1.11 \pm 0.05^{*}$ \\
\hline $22: 6(n-3)$ & 0.91 & $8.89 \pm 0.31$ & $22.52 \pm 0.95^{*}$ \\
\hline SFA & 17.23 & $48.51 \pm 2.43$ & $25.33 \pm 1.21^{*}$ \\
\hline UFA & 82.77 & $51.49 \pm 2.93$ & $74.67 \pm 2.89^{*}$ \\
\hline $\operatorname{MUFA}(n-9)$ & 54.91 & $14.83 \pm 0.81$ & $14.96 \pm 0.84$ \\
\hline PUFA & 27.86 & $36.66 \pm 1.78$ & $59.71 \pm 2.11^{*}$ \\
\hline$n-3$ PUFA & 1.37 & $9.72 \pm 0.32$ & $23.63 \pm 1.12^{*}$ \\
\hline$n-6$ PUFA & 26.49 & $26.94 \pm 1.29$ & $36.08 \pm 1.77^{*}$ \\
\hline$n-3$ PUFA/n-6 PUFA & 0.05 & $0.36 \pm 0.02$ & $0.65 \pm 0.04^{*}$ \\
\hline PUFA/SFA & 1.62 & $0.75 \pm 0.03$ & $2.35 \pm 0.15^{*}$ \\
\hline PUFA:MUFA:SFA & $1.62: 3.19: 1.00$ & $0.75: 0.31: 1.00$ & 2.35:0.59:1.00* \\
\hline Unsaturation index & 119.10 & 150.63 & 258.74 \\
\hline Triacylglycerol $^{+}$ & 84.25 & - & \\
\hline Monoacylglycerol $^{+}$ & 10.31 & - & - \\
\hline Cholesterol $^{+}$ & 4.31 & - & - \\
\hline Free fatty acids ${ }^{+}$ & 1.13 & - & - \\
\hline
\end{tabular}

Mice (25-30 g) received the oil $(0.4 \%$ of body weight) by gavage daily for 4 weeks. Data are reported as the mean \pm SEM of percent recovered fatty acids by weight for three determinations in each of the 6 mice in each group. SFA = sum of saturated fatty acids (FA); UFA = sum of unsaturated FA; MUFA = sum of monounsaturated FA; PUFA: sum of polyunsaturated FA; $n-3$ PUFA $=$ sum of $n-3$ PUFA; $n-6$ PUFA $=$ sum of n-6 PUFA. + Lipid class composition (\%).

${ }^{*} \mathrm{P}<0.05$ compared to control (one-way ANOVA and Scheffé's test). 
PUFA, the liver of bullfrog oil-treated animals had a higher proportion $(\mathrm{P}<0.05)$ of $22: 6 n-3(153 \%)$ and $20: 5 n-3(34 \%)$ and a decreased proportion of $18: 3 n-3(60 \%)$. A 29 and $42 \%$ increase of $20: 4 n-6$ and 18:2n-6 was observed in $n-6$ PUFA, respectively ( $\mathrm{P}<$ $0.05)$. No significant differences were observed in the proportion of MUFA between groups.

TBARS content (Table 2) in the liver of bullfrog oil-treated animals changed from $2.3 \pm 0.2$ to $12.3 \pm 0.3$ nmol TBA-MDA formed per mg protein $(435 \%)$. Catalase activity (Table 2) was increased by bullfrog oil administration from $840 \pm 32$ to $1110 \pm 45$ $\mu$ mol reduced $\mathrm{H}_{2} \mathrm{O}_{2}$ min $^{-1} \mathrm{mg}$ protein ${ }^{-1}(32 \%)$.

AST, ALT, and ALP activities were increased by 46,10 , and $114 \%$, respectively, in the liver of bullfrog oil-treated animals compared to the control $(\mathrm{P}<0.05)$. There was a statistically significant 26 and $8 \%$ increase in AST and ALP activities, respectively, in the serum of bullfrog oil-treated mice (Table 2), but no significant effect on ALT activity in serum, or on GGT activity in liver and serum (Table 2).

As previously mentioned, bullfrog oil is a MUFA-rich animal-derived oil. MUFA ( $n-9$ and $n-7$ ) account for $55 \%$ of total FA, con- sisting of $38 \%$ oleic acid (18:1n-9) and $17 \%$ palmitoleic acid (16:1n-7). Linoleic acid $(18: 2 n-6)$ was the second most abundant FA (24\%) and accounted for almost $100 \%$ of $n$ $6 \mathrm{FA}$ in bullfrog oil. Bullfrog oil was poor in linolenic acid (18:3n-3) and in FA containing 20 or more carbons (Table 1). Although bullfrog oil is similar to canola oil in terms of total PUFA and MUFA, the former contains almost $100 \%$ more oleic acid and $350 \%$ more linolenic acid (ALA), as well as about $200 \%$ less total SFA than the latter.

The influence of dietary lipids on liver FA composition has been demonstrated in experimental animal studies using different oils $(1,14,15)$. In the present study, intragastric administration of bullfrog oil caused an increase in long-chain PUFA (20:4n-6, 20:5n-3, and 22:6n-3) and a decrease in SFA (14:0, 16:0, and 18:0) in the liver. Bullfrog oil led to an increase in total liver PUFA, $n-3$ PUFA, and $n-6$ PUFA, concomitant with a decrease in total SFA. Total MUFA content did not differ between groups, although bullfrog oil-treated liver had a higher relative content of these FA.

Arachidonic acid (AA), eicosapentaenoic acid (EPA), and docosahexaenoic acid (DHA) are PUFA obtained from the diet or

Table 2. Effect of intragastric bullfrog oil administration on TBARS, catalase, alkaline phosphatase, and aminotransferase activities of mouse liver and serum. Bullfrog oil administration is described in the legend to Table 1.

\begin{tabular}{|c|c|c|c|c|}
\hline & \multicolumn{2}{|c|}{ Liver } & \multicolumn{2}{|c|}{ Serum } \\
\hline & $\begin{array}{l}\text { Control } \\
\text { group }\end{array}$ & $\begin{array}{l}\text { Bullfrog oil-treated } \\
\text { group }\end{array}$ & $\begin{array}{l}\text { Control } \\
\text { group }\end{array}$ & $\begin{array}{c}\text { Bullfrog oil-treated } \\
\text { group }\end{array}$ \\
\hline TBARS (nmol/mg protein) & $2.3 \pm 0.2$ & $12.3 \pm 0.3^{*}$ & - & - \\
\hline Catalase ( $\mu \mathrm{mol} \mathrm{min}^{-1} \mathrm{mg}$ protein ${ }^{-1}$ ) & $840 \pm 32$ & $1110 \pm 45^{*}$ & - & - \\
\hline AST ( $U / g$ in liver and $U / I$ in serum) & $234.10 \pm 0.12$ & $342.84 \pm 0.13^{*}$ & $95.41 \pm 6.13$ & $120.32 \pm 3.15^{*}$ \\
\hline ALP ( $U / g$ in liver and $U / l$ in serum) & $9.38 \pm 0.60$ & $20.06 \pm 0.27^{*}$ & $234.75 \pm 11.50$ & $254.41 \pm 2.73^{*}$ \\
\hline ALT (U/g in liver and $U / l$ in serum) & $287.28 \pm 0.29$ & $315.98 \pm 0.34^{*}$ & $74.00 \pm 10.58$ & $71.98 \pm 4.25$ \\
\hline GGT (U/g in liver and $U / l$ in serum) & $0.22 \pm 0.03$ & $0.16 \pm 0.09$ & $24.52 \pm 3.71$ & $20.25 \pm 1.50$ \\
\hline
\end{tabular}

Data are reported as the mean \pm SEM of three determinations in each of the 6 mice in each group. AST $=$ aspartate aminotransferase; $A L T$ = alanine aminotransferase; $A L P=$ alkaline phosphatase; $G G T$ = gammaglutamyltransferase; TBARS $=$ thiobarbituric acid reactive substances. One unit of the aminotransferases and ALP is defined as the amount of enzyme required to produce $1 \mu \mathrm{mol}$ of NAD or p-nitrophenol, respectively, per minute under the conditions of the assay.

${ }^{*} \mathrm{P}<0.05$ compared to control (one-way ANOVA and Scheffé's test). 
synthesized from their direct precursors, linoleic acid for AA and ALA for EPA and DHA, in a process involving elongase/desaturase enzymes. Therefore, the relative increase of AA in the liver of bullfrog oiltreated animals may be explained by direct incorporation and/or by formation from its precursor, since it is present in relatively high amounts in bullfrog oil compared to other oils. Similarly, the increase in EPA and DHA may be explained by direct incorporation and/or synthesis from ALA present in bullfrog oil. An increase in the proportions of total $n$-3 PUFA in brain and liver (including EPA and DHA) has been observed in a number of studies involving feeding of olive oil, which contains a low proportion of $n-3$ PUFA and its precursors $(15,16)$. Interestingly, in the present study the incorporation of $n-9$ FA was very low. Weber et al. (17), studying the metabolism of mead acid (20:3n9), observed an accumulation of $n-3$ and $n-6$ products such as DHA, EPA, and AA, as also observed in the present study. These investigators proposed that a feedback mechanism might down-regulate the $n-9$ pathway in the liver, preventing further conversion of dietary precursors and/or direct incorporation. In this case, $n-9$ FA catabolism might be stimulated. Sprecher et al. (18) studying $n$-6 FA, also suggested an inverse relationship between rates of peroxisomal B-oxidation and FA esterification.

Increased catabolism via peroxisomal Boxidation leads to an in vivo increase of hydrogen peroxide production that is potentially toxic to the cell. Catalase is predominantly found in the peroxisomes of most cells and converts hydrogen peroxide to oxygen and water, preventing oxidative stress and playing an antioxidant defense role (19). Supporting the postulated increase in peroxisomal $\beta$-oxidation in bullfrog oil-treated animals, there was an increase in liver catalase activity. The increase in the activity of this enzyme is perhaps an attempt to protect against hydrogen peroxide toxicity.
An increase in the proportion of PUFA in the membranes and of the unsaturation index was directly associated with the elevation of membrane lipid peroxidation. Lipid peroxidation is a highly destructive phenomenon that propagates free radicals and leads to the release of a wide variety of relatively stable breakdown products known to be toxic. Our study showed an elevated TBARS content in the liver of bullfrog oil-treated animals, which was associated with the increase in the PUFA/SFA ratio (Table 1). These results agree with previous studies indicating that a high PUFA/SFA ratio in the diet is partially responsible for the increase of TBARS content leading to histological and functional damage in the liver (20).

AST, ALT, GGT, and ALP activities serve as biomarkers of liver injury (20). It is generally assumed that an increase of these enzyme activities reflects active inflammation and necrosis of hepatic cells, whereas a decrease indicates a decline of hepatic inflammation and may lead to morphological improvement (20). Our results indicate that the increase in lipid peroxidation in the liver of bullfrog oil-treated animals promoted damage to liver cells, which led to an increase of AST, ALT, and ALP activities in the liver. However, in spite of this, an increase $(\mathrm{P}<$ 0.05 ) of the AST and ALP activities, but not of ALT, was observed in blood serum. These results suggest that bullfrog oil supplementation can promote damage to the liver. This small change, however, did not lead to morphological changes or leukocyte infiltration, as observed by light microscopy of the liver (data not shown).

Intragastric treatment of mice with bullfrog oil promotes elevation of the relative amount of PUFA (such as AA, EPA, and DHA) and a decrease in SFA (14:0, 16:0, and 18:0) in the liver. Bullfrog oil supplementation also led to an increase of TBARS content in the liver and of AST and ALP activities in serum, suggesting that this treatment induces tissue damage. 


\section{Acknowledgments}

We thank Rander Ltda. (Brasília, DF, Brazil) for providing the bullfrog oil used in this study, and Laboratório Sabin (Brasília) for determination of the enzyme activities using the ADVIA 1650 system.

\section{References}

1. Pompeia C, Freitas JJS, Kim JS, Zyngier SB \& Curi R (2002). Arachidonic acid cytotoxicity in leukocytes: implications of oxidative stress and eicosanoid synthesis. Biology of the Cell, 94: 251-265.

2. Yaqoob P (1998). Monounsaturated fat and immune function. Proceedings of the Nutrition Society, 57: 511-520.

3. Pereira B, Costa-Rosa LFBP, Bechara EJH, Newsholme P \& Curi R (1998). Changes in the TBARs content and superoxide dismutase, catalase and glutathione peroxidase activities in the lymphoid organs and skeletal muscles of adrenodemedullated rats. Brazilian Journal of Medical and Biological Research, 31: 827-833.

4. Pompeia C, Lopes LR, Miyasaka CK, Procopio J, Sannomiya P \& Curi R (2000). Effect of fatty acids on leukocyte function. Brazilian Journal of Medical and Biological Research, 33: 1255-1268.

5. Albuquerque KT, Ramalho RA, Soares AG \& Tavares-do-Carmo MG (1998). Effects of ethanol intake on retinol concentration in the milk of lactating rats. Brazilian Journal of Medical and Biological Research, 31: 929-932.

6. Maggi-Capeyron MF, Cases J, Badia E, Cristol JP, Rouanet JM, Besançon P, Leger CL \& Descomps B (2002). A diet high in cholesterol and deficient in vitamin $\mathrm{E}$ induces lipid peroxidation but does not enhance antioxidant enzyme expression in rat liver. Journal of Nutritional Biochemistry, 13: 296-301.

7. Tran TN, Retterstol K \& Christophersen BO (2001). Differences in the conversion of the polyunsaturated fatty acids $\left[1-{ }^{14} \mathrm{C}\right] 22: 4(n-6)$ and $\left[1-{ }^{14} \mathrm{C}\right] 22: 5(n-3)$ to $\left[{ }^{14} \mathrm{C}\right] 22: 5(n-6)$ and $\left[{ }^{14} \mathrm{C}\right] 22: 6(n-3)$ in isolated rat hepatocytes. Biochimica et Biophysica Acta, 1532: 137-147.

8. Kushiro M, Masaoka T, Hageshita S, Takahashi Y, Ide T \& Sugano M (2002). Comparative effect of sesamin and episesamin on the activity and gene expression of enzymes in fatty acid oxidation and synthesis in rat liver. Journal of Nutritional Biochemistry, 13: 289295.

9. Abushufa R, Reed P \& Weinkove C (1994). Fatty acids in erythrocytes measured by isocratic HPLC. Clinical Chemistry, 40: 17071712.
10. Miyasaka CK, Mendonça JR, Nishiyama-Naruke A, Alves de Souza JA, Pires de Melo M, Pithon-Curi TC \& Curi R (2001). Comparative effects of fish oil by gavage and fish oil-enriched diet on leukocytes. Life Sciences, 69: 1739-1751.

11. Winterbourn CC, Gutteridge JM \& Halliwell B (1985). Doxorubicin dependent lipid peroxidation at low pressures of $\mathrm{O}_{2}$. Free Radical Biology and Medicine, 1: 43-49.

12. Beutler E (1975). Red Cell Metabolism: A Manual of Biochemical Methods. Grune \& Stratton, New York, 89-90.

13. Bradford MA (1976). A rapid and sensitive method for the quantification of microgram quantities of protein utilizing the principle of protein-dye binding. Analytical Biochemistry, 72: 248-254.

14. Jeffcoat $R$ (1979). The biosynthesis of unsaturated fatty acids and its control in mammalian liver. Essays in Biochemistry, 15: 1-36.

15. Weber N \& Mukherjee KD (1998). Steep rise of docosahexaenoic acid in phosphatidylethanolamines of heart and liver of rats fed native olive oil or rapeseed oil. Nutrition Research, 18: 851-861.

16. Brenner RR, Ayala S \& Garda HA (2001). Effect of dexamethasone on the fatty acid composition of total liver microsomal lipids and phosphatidylcholine molecular species. Lipids, 36: 1337-1345.

17. Weber N, Vosmann K, Bruhl L \& Mukherjee KD (1997). Metabolism of dietary petroselinic acid: A dead-end metabolite of desaturation/ chain elongation reactions. Nutrition Research, 17: 89-97.

18. Sprecher H, Luthria DL, Mohammed BS \& Baykousheva SP (1995). Reevaluation of the pathway for the biosynthesis of polyunsaturated fatty acids. Journal of Lipid Research, 36: 2471-2477.

19. Miyasaka CK, de Souza JAA, Torres RP, Mancini J, Lajolo FM \& Curi $R$ (1998). Effect of the administration of fish oil by gavage on activities of antioxidant enzymes of rat lymphoid organs. General Pharmacology, 30: 759-762.

20. Hwang DF, Hour JL \& Cheng HM (2000). Effect of taurine on toxicity of oxidized fish oil in rats. Food and Chemical Toxicology, 38: 585-591. 